\title{
A Case Study on Faculty and Professional Advisor Perceptions on Academic Advising
}

\author{
Agatha O'Brien-Gayes and Kerry Spitze
}

This case study addresses the attitudes and perceptions of faculty and professional advisors at a public comprehensive liberal arts institution. Based on a survey administered to full-time faculty and professional advisors in Fall 2009, the results showed a quantitative difference in levels of satisfaction with advising between the groups. Faculty reported a desire to function more in a mentoring capacity as well as increased recognition for advising during the promotion and tenure process, and identified a systemic need for better communication of policies and procedures. Professional advisors also raised these concerns but reported a higher level of overall satisfaction with advising. Concrete strategies to improve advising delivery were identified. Some preliminary best practices are addressed.

Several themes are identified in considering perceptions towards academic advising but have not been well quantified by formal surveys. This case study focuses on a southeastern public comprehensive liberal arts institution with approximately 8,100 students, utilizing a diverse advising system which provides an ideal environment for a case study of advising perceptions. The aim of this study was to gather baseline data on the perceptions and attitudes towards advising from a faculty and professional advisor standpoint. A data driven context could then be provided to guide recommendations for modifications to systemically improve advising delivery and perhaps overall satisfaction.

The university highlighted in this study utilizes a split model of advising: professional advisors assist all freshmen and undeclared students, two out of four colleges utilize professional advisors for sophomores, and faculty members advise all other students. Collectively, disparate approaches to post first-year advising needs have evolved. This may be particularly challenging to students who change majors and potentially experience a considerable change in advising delivery (e.g., philosophical approach, structure, and emphasis).

There is a clear relationship between student retention and effective advising (Lotkowski, Robbins, \& Noeth, 2004; Habley \& McClanahan, 2004; Gordon, Habley, \& Grites, 2008). Through understanding the current attitudes of those engaged in advising, the hope is to foster improvements in the advising process

Agatha O'Brien-Gayes (aobrieng@coastal.edu) is the Director of First-Year Academic Advising at Coastal Carolina University.

Kerry Spitze (kespitze@syr.edu) is a doctoral student at Syracuse University. 
to not only enhance support of individual student needs, but also institutional ambitions for increased student retention. One initial premise for the present work was that improvement in both areas might be accomplished through gaining consistency in delivery. Institutional assessment has also become critical in planning for sustained growth, which places pressures and constraints on the scale of advising delivery. This case study also proposes that to ensure effective advising at all levels of a student's experience, there needs to be clarity in how advising is viewed and provided so that appropriate modifications can be made to improve the system.

\section{Literature Review}

Research within the field of academic advising contains a dearth of studies that report on faculty attitudes/perceptions toward academic advising as well as satisfaction with the advising process (Harrison, 2009; Donnelly, 2009; Allen \& Smith, 2008). There is little delineation made within the literature for perception and satisfaction between faculty advisors and professional advisors (Allen \& Smith, 2008). The predominant focus of published studies has been on student perception and satisfaction with advising (Harrison, 2009). Because there is such a high percentage of faculty members who are responsible for advising (Habley, 2003), their attitudes and perceptions as well as levels of satisfaction are vital to the effective delivery of advising. If there is no faculty "buy-in" or commitment to quality academic advising, it is logical to presume that there will be decreased value placed on advising, inconsistencies in the delivery of advising, and negative student experiences with advising. Professional advisors' perceptions and attitudes towards advising are also critical in identifying best practices. Since professional advisors are more focused on the advising process, staying current in prevailing thinking on advising, and in changing requirements and information across the full spectrum of colleges and departments, they should be particularly skilled and effective in advising students.

Previous studies report that faculty view advising as having a lower status among their job functions (research, teaching, and service activities) and perceive advising to have lesser value to the university administration, particularly as it is generally not considered within the promotion and tenure review (Allen \& Smith, 2008; Dillon \& Fisher, 2000). Myers and Dyer (2005) conducted a survey of faculty attitudes toward advising and found that although the majority of the faculty did not believe advising was a part of the promotion and tenure process, there was value to overall advising. However, "it is to be expected that the lack of importance given to advising activities in promotion and tenure decisions would have a negative effect on motivation towards advising" (Myers \& Dyer, 2005, p. 43).

Additionally, a study conducted by Allen and Smith (2008) shows that faculty believe advising functions to have value to students, but faculty members do not necessarily believe they are responsible for delivering all identified functions. It should be expected that advising is viewed as a more central and valued job function for professional advisors with commensurate satisfaction and enthusiasm 
for the process. Regarding overall satisfaction with advising, Donnelly (2004) stated, "Findings support the proposition that the more connected advisors are to standards for practice, the greater the job satisfaction" (p. 34). Donnelly's findings also indicate that "student centeredness and availability of advisingrelated information resources were antecedents of job satisfaction among academic advisors" (p. 34). This suggests that advising standards and resources need to be communicated and clarified among both professional advisors and faculty who advise students.

Job satisfaction has also been studied extensively outside of academic advising in organizational behavior. Herzberg (1968) developed the Two Factor Theory, which identifies factors affecting job attitudes into two categories: those factors leading to dissatisfaction and those leading to satisfaction. Those leading to dissatisfaction include pay and benefits policies and administration, relationships with co-workers, quality of supervision, status, security, working conditions, and personal life. Those leading to satisfaction are achievement, recognition, the work itself, responsibility, promotion, and growth.

Since the formation of the National Academic Advising Association (NACADA) over the last 32 years, advising has begun to shift in some institutions from purely faculty advising to offices staffed with professional advisors (Cook, 2009). The satisfaction levels of both groups have been addressed, albeit infrequently, in the literature. In a study by Donnelly (2009), 46\% of advisors surveyed (encompassing both professional advisors and faculty) identified dissatisfaction with salary, $33 \%$ with a lack of recognition, and 26\% identified a lack of career opportunity as leading parameters influencing dissatisfaction. Salary issues can lead to dissatisfaction, but do not, on their own, create satisfaction: "Neither salary nor benefits showed a high correlation with overall satisfaction, and they held the lowest and second lowest position among correlated predictor variables" (Donnelly, 2009, p. 12). According to Donnelly (2009), variety, empowerment, and teamwork emerged as the top three variables within advising that had the strongest correlation to overall satisfaction.

Recent publications indicate that training and information are key aspects to effective and satisfying advising among both faculty and professional advisors (Harrison, 2009; Donnelly, 2009; Dillon \& Fisher, 2000). Myers and Dyer (2005) noted that "many of the [faculty] advisors in this study had little to no professional preparation to advise students or student organizations" (p. 44). They also reported that only about one-third of universities and colleges provide professional development within the field of advising. Dillon and Fisher (2000) indicated that "faculty members who have advised for some time sometimes do not receive the appropriate information or instruction on course changes and sequencing of curriculum guidelines" (p. 16). Although the literature also indicates that those institutions offering professional development and training have few faculty members who participate (Allen \& Smith, 2008; Myers \& Dyer, 2005), this is most likely because of the lack of impact advising has within the promotion and tenure process rather than a lack of the need for professional development and training. 


\section{Method}

A survey was developed using a mixed method approach to compile a comprehensive data set assessing satisfaction and perceptions of full-time faculty members and professional advisors. The survey, which was modified, with permission, from an assessment created by Cuseo (2003), was administered in an online format to 335 faculty and nine professional advisors.

TABLE 1

\section{Demographics of Respondents by Advising Role and Home College}

(Responses are also shown as a percentage of the eligible members of the various populations.)

\begin{tabular}{lccc}
$\begin{array}{c}\text { Home } \\
\text { College }\end{array}$ & $\begin{array}{c}\text { Faculty Advisors } \\
\text { Responses / Total (\%) }\end{array}$ & $\begin{array}{c}\text { Professional Advisors } \\
\text { Responses / Total (\%) }\end{array}$ & $\begin{array}{c}\text { Total } \\
\text { Responses }\end{array}$ \\
\hline Business & $12 / 48(25 \%)$ & $1 / 1(100 \%)$ & 13 \\
Humanities & $18 / 126(14 \%)$ & NA & 18 \\
Science & $27 / 108(25 \%)$ & NA & 27 \\
Education & $2 / 44(5 \%)$ & $1 / 1(100 \%)$ & 3 \\
Advising Center & NA & $7 / 7(100 \%)$ & 7 \\
TOTAL & $59 / 326(18 \%)$ & $9 / 9(100 \%)$ & $68 / 335$
\end{tabular}

\section{Data Collection}

The survey was e-mailed to all faculty and professional advisors explaining the objective of the project and requesting individuals to participate by following the Web link and completing the online survey within 10 days. Results were compiled in a database maintained by the university's Office of Institutional Research, with all results being electronic and anonymous other than generic demographic information. The survey was initiated on August 25, 2009-a time frame free of numerous organized campus wide initiatives or other drivers on the academic calendar to maximize responses from as many advisors and faculty as possible. Survey questions were structured to generate both quantitative and qualitative responses from each participant. The primary thematic areas of the survey were: 1) faculty and professional advisor attitude towards advising, 2) perception of student attitude towards advising, 3) areas where improvements could be made to the process, and 4) needs for individual or institutional support to improve advising and professional satisfaction. 


\section{Results}

Tables $2 \mathrm{a}$ and $2 \mathrm{~b}$ show the results of the quantitative portion of the survey identifying parameters assessed. The results are broken down by the role of the respondent; for faculty responses, the respondent's home college was used to sub-set the data.

TABLE 2a

Survey responses for number of advisees, years of
experience advising, and attitude towards advising

\begin{tabular}{|l|c|c|c|c|c|c|}
\hline Number of Advisees & $<50$ & $51-$ & $\mathbf{1 0 1 -}$ & $\mathbf{1 5 0 -}$ & $\mathbf{2 0 1 -}$ & $\mathbf{2 5 1 -}$ \\
& & $\mathbf{1 0 0}$ & $\mathbf{1 5 0}$ & $\mathbf{2 0 0}$ & $\mathbf{2 5 0}$ & $\mathbf{3 0 0}$ \\
\hline Faculty & 46 & 12 & 1 & 1 & 0 & 0 \\
\hline Advisors & 0 & 0 & 0 & 0 & 1 & 8 \\
\hline
\end{tabular}

\begin{tabular}{l|c|c|c|c|}
\hline Years Experience & $<10$ & $11-20$ & $21-30$ & $31-40$ \\
\hline Faculty & 34 & 16 & 7 & 4 \\
Advisors & 9 & 0 & 0 & 0 \\
\hline
\end{tabular}

\begin{tabular}{|c|c|c|c|c|}
\hline \multicolumn{2}{|c|}{ Attitude Towards Advising } & \multirow{2}{*}{$\begin{array}{c}\text { Pleasant and } \\
\text { Rewarding } \\
35\end{array}$} & \multirow{2}{*}{$\begin{array}{c}\text { Neutral } \\
\\
13\end{array}$} & \multirow{2}{*}{$\begin{array}{c}\text { Unpleasant } \\
13\end{array}$} \\
\hline Perception & Faculty & & & \\
\hline of faculty & Advisors & 9 & 0 & 0 \\
\hline Perception & Faculty & 12 & 35 & 13 \\
\hline of Students & Advisors & 5 & 4 & 0 \\
\hline
\end{tabular}




\section{Survey responses characterizing advising experiences}

Academic Advising Experience Best Characterized By:

\begin{tabular}{|c|c|c|}
\hline & Faculty & Advisors \\
\hline Students often do not keep appointments. & $61(100 \%)$ & $3(33 \%)$ \\
\hline $\begin{array}{l}\text { Students often do not come with any } \\
\text { pre-planned schedule. }\end{array}$ & $57(93 \%)$ & $7(78 \%)$ \\
\hline $\begin{array}{l}\text { I give accurate advice and answers to } \\
\text { curriculum questions. }\end{array}$ & $48(79 \%)$ & $7(78 \%)$ \\
\hline $\begin{array}{l}\text { I give accurate advice and answers to questions } \\
\text { relating to post graduation options. }\end{array}$ & $44(72 \%)$ & $6(67 \%)$ \\
\hline $\begin{array}{l}\text { I serve as a resource person for advisees relating } \\
\text { to choice of college major. }\end{array}$ & $39(64 \%)$ & $8(89 \%)$ \\
\hline $\begin{array}{l}\text { I serve as a resource person on matters related } \\
\text { to career choice. }\end{array}$ & $36(59 \%)$ & $6(67 \%)$ \\
\hline $\begin{array}{l}\text { I help my advisees to resolve their } \\
\text { personal problems. }\end{array}$ & $40(66 \%)$ & $4(44 \%)$ \\
\hline $\begin{array}{l}\text { I refer my advisees to campus support services } \\
\text { for assistance on matters beyond my expertise. }\end{array}$ & $34(56 \%)$ & $9(100 \%)$ \\
\hline $\begin{array}{l}\text { I encourage my advisees to become involved in } \\
\text { campus life and in service off the campus } \\
\text { community. }\end{array}$ & $14(23 \%)$ & $8(89 \%)$ \\
\hline
\end{tabular}

The quantitative data indicated that the majority of faculty members saw advising as pleasant and rewarding. There was also a fairly equal split among faculty who saw advising as unpleasant or had neither positive nor negative feelings towards advising. An overwhelming majority indicated that students held a more neutral stance towards advising, feeling neither positive nor negative regarding the process.

For reporting purposes, the qualitative responses culled from the survey have been identified as themes within the following categories: attitude towards 
advising, student attitudes towards advising, college response to current advising system, rewarding aspects of advising, frustrating/dissatisfying aspects of advising, how to improve advising on campus, and institutional support for the process of advising.

Within the category of attitude towards advising, areas of recurring themes that arose. Themes required a minimum of five detailed responses out of forty to be considered recurrent. These themes were as follows:

- advising information specific to career/discipline (5);

- a lack of student preparedness and responsibility (9);

- internal policy issues and inconsistencies (7);

- lack of professional development and training (5);

- satisfaction with advising (18);

- time constraints (10);

- registration issues including closed required classes, frequency of catalog changes, frequent core curriculum changes (5).

The following responses captured faculty frustrations and concerns:

“... [Advising] is not rewarding as far as the university goes-it takes time away from research and writing and therefore works against the faculty members' best interests."

"It is a time consuming process for which we get no recognition."

Faculty respondents indicated a positive experience when allowed to go into depth with advisees on career and discipline-related issues. They further indicated enjoying working one-on-one with students in their discipline, with this theme emerging as the most positive and satisfying aspect to advising. Conversely, the theme that emerged as the least satisfying was working with unprepared advisees, addressing minutiae of policy, and dealing with concerns that advising is not part of the tenure and review process.

One-hundred percent of professional advisors reported finding advising pleasant and rewarding compared to $57.38 \%$ of faculty. The comments provided by professional advisors indicated satisfaction with the various facets of developmental advising. Advisors noted satisfaction through problem solving, planning, interacting/advocating for students, and getting to know their advisees as individuals. The frustrations noted involved those peak periods when advising takes on a prescriptive tone due to time constraints, the repetitiveness of certain aspects (paperwork/course descriptions), and bureaucratic obstacles.

Within the category of student attitudes, faculty respondents reported a range of perceived student attitudes from pleasant and rewarding to an unpleasant experience. This further broke down into several identifiable issues. The majority of respondents reported that the key factors for a positive advising experience included the preparedness of the student and the existing relationship between the student and advisor. The lack of cohesion in terms of an institutional approach to 
advising, which is shown as varying by college, was repeatedly referenced as leading to negative student attitudes. A student in an institution with a decentralized advising system may have up to four advisors as they progress through their college career, thus making the student experience variable.

Even though the questions addressed student attitudes, faculty included their own personal frustrations within their responses. Student apathy and indifference to advising was also identified: "They don't like the fact that they have to prepare for advising outside the advising process. They want to show up with no idea of courses they need or want to take, and hope that in the 30 minutes I have to work with them, that we will get a perfect schedule."

Fifty-six percent of professional advisors reported students found the advising process pleasant and rewarding compared to $20 \%$ of faculty respondents. Professional advisors (like faculty) included their own attitudes and perceptions in their responses. Both groups also addressed the importance of establishing a working advisor/advisee relationship in determining student satisfaction. Both groups also addressed the lack of cohesion as an institution adversely impacting student satisfaction.

Within the category of the most rewarding aspect of academic advising, respondents indicated it was seeing advisees succeed academically. This was followed by the quality of interpersonal relationships with students. Faculty indicated that being able to help students was rewarding, from seeing their ambitions realized to seeing them graduate and take responsibility for their own success. Student growth and development was clearly a rewarding part of the advising process for faculty as was the underlying theme of mentoring. Student growth and development was also the most rewarding aspect for the professional advisors. Professional advisors reported enjoyment through making connections with advisees, helping advisees achieve their goals and meet challenges, solve problems, and make informed decisions. There were no negatives reported.

The next category seeks to identify the most dissatisfying aspects of advising within the institution. Students' lack of preparedness was the number one factor that faculty identified as dissatisfying. A close second was lack of student responsibility and class/curricula issues. One respondent stated, "Constantly changing curriculum and curriculum nuances, no training in advisement process, program evaluation is almost always inaccurate, therefore useless..." captured the essence of the issue. Dissatisfaction with time demand was also noted as one of the main factors contributing to faculty frustration with the process. Student apathy was also identified repeatedly by faculty.

Professional advisors echoed faculty responses regarding dissatisfaction. Those included: lack of student responsibility, curricula changes, institutional bureaucracy, and students with a sense of entitlement ("there was a time when an education was seen as a privilege"), lack of student initiative, time constraints due to caseload, and the exponential growth of the institution without an adequate plan to handle it effectively. Professional advisors also identified the issue of helicopter parents as lending to dissatisfaction.

The survey asked respondents to indicate how advising could be improved, and 
the number one response from faculty was to go to a model with all professional advisors:

There is considerable advantage to a centralized advisement /registration function to address consistency, knowledge of more than one major, and up-to-date familiarity with the full range of resources and offices available to aid students. Departmental advising should parallel and relate to the areas that faculty are more familiar and trained, how to best help students advance in their specialized field areas.

Lack of training was the second most identified factor or theme within this category.

In terms of improving the advising system campus wide, professional advisors articulated very different approaches with the exception of having more professional advisors and having a more unified campus advising model. Professional advisors addressed a much broader range of suggestions including: streamlining forms and administrative processes, encouraging student responsibility and decreasing advisor dependency, staying within NACADA caseload guidelines, improving technology, stopping mid-year changes to the catalog with policies and procedures, improving communication between the administration and the departments, and including advising in the review process for anyone on campus who has the role of an advisor.

The last category of the survey requested that respondents identify institutional support that would improve the process. These responses mirrored the previous categorical responses for faculty. Professional advisors also addressed the lack of portability of the core curriculum and the importance of not only reevaluating the core but raising caps in core classes. A lack of communication between departments was also an issue for advisors. Professional advisors requested institutional support for outside training and professional development as well as identified a concern about caseloads.

\section{Discussion}

There were notable differences in overall satisfaction levels between professional advisors and faculty members who completed the survey. Whereas all professional advisors surveyed indicated that they found the advising process satisfying, only slightly more than half of faculty advisors shared the same level of satisfaction. This distinction is not necessarily indicative of a larger national trend among those who advise. In another survey of both full-time advisors and faculty advisors, Donnelly (2009) indicated, "Full-time advisors are no more satisfied than faculty advisors either overall or with regard to the student and supervision aspects of advising" (p. 8).

One explanation for the findings from this study may be that professional advisors surveyed focus primarily on providing academic advising, and job duties do not include a research component or a full-time teaching load. Additionally, professional advisors surveyed in this study may have had more training in how to 
provide quality academic advising, and they may be more in sync with the changes in policy and procedure of the university due to job requirements. Nonetheless, the majority of respondents from both parties reported that they found certain aspects of advising pleasant and rewarding with some differences by college and a noted disparity between quantitative questions and qualitative comments. One possible explanation may be that the institution had not previously given faculty and professional advisors an opportunity through a campus-wide assessment to express their views on the process of advising.

Faculty report satisfaction in assisting students with career development and planning, but are frustrated with the mechanics of the process, from the size of caseloads and perceived inequities to policy, registration, and curriculum issues. The noted class/curricula issues can be tied to the growth rates at this particular institution, which have doubled in the last nine years. With the number of students exceeding the number of seats available in classes, this imbalance complicates the advising and registration process. Additionally, constant catalog changes make the catalog obsolete midyear, leading to a lack of confidence in the catalog and its consistent use, and a lack of dissemination of information from administration when changes are made mid-year. The frustrations noted by faculty advisors are similar to those found by Allen and Smith (2008), whose findings indicated that faculty advisors rated the information functions of advising ("How Things Work," "Gen Ed Connect," and "Nonacademic Referral") low in terms of overall satisfaction.

From a faculty perspective, advising was not seen as being a part of the promotion and tenure process: "Too many advisees to balance other responsibilities; imbalance of advising load across campus (some faculty have only a few), and despite what one might hear concerning this, advising is not recognized for [promotion and tenure] (at any level-department, school, university)." This issue has been seen elsewhere: "... higher education administrators must begin to intentionally and creatively redesign traditional reward systems to place higher value on academic advisement as a professional responsibility" (Cuseo, 2005, p. 16). According to Habley (2003), only 31\% of institutions provide any form of recognition, reward, or compensation for advising. Currently, teaching, research, scholarly publication, and grant funding all precede advising in level of importance for promotion and tenure, and advising is not formally identified as influencing annual reviews and promotions in many department/college guidelines (Allen \& Smith, 2008).

While advising should be part of a formal review process for faculty, professional advisors should be seen and respected as an integral and crucial piece of the academic component necessary for student success. The lack of faculty standing contributes to a level of frustration as professional advisors. The organizational structure of a postsecondary institution precludes professional advisors from many of the committees and bodies creating the policies that directly impact student success. Professional advisors are caught in a position of having accountability without authority. These findings echo those by Donnelly (2009) whose study indicated that advisors desire more empowerment, which was defined 
as "the authority to make significant decisions on behalf of the institution when working with students" (p. 11).

As identified by both groups, a consensus is developing for a centralized advising delivery system beyond the first year. The findings do not support faculty abdicating all aspects of advising, but rather limiting their advising role to mentoring in their field in terms of professional development of the student and not focusing on internal policy and procedural issues. These findings seem to echo those of Allen and Smith (2008) whose study indicated support for a dual model of advising. This model provides the students with two advisors: a faculty advisor who guides students within their specific major field of study, and a professional advisor who assists students with matters outside of the students' major (how to register, interpreting policy and procedure) (Gordon et al., 2008).

An interesting and insightful outlier, addressing the rapid growth of the institution, suggested increasing enrollment standards. By increasing the quality of student (i.e., through implementing an enrollment process more selective in nature which includes but is not limited to average SAT and/or ACT scores and/or core high school grade point average), there may be an underlying belief that this would diminish student apathy and unpreparedness. Because many public institutions are increasingly tuition driven, the concept of advising as customer service may be an underlying source of faculty and professional advisors' frustrations.

The study also highlighted a systemic lack of communication that stems from the disparate models used and maintained at different structural levels (departments/colleges). Growth can challenge traditional methods of communication for rapidly growing institutions where the traditional communication framework may no longer work efficiently for the new scale and complexity of larger institutions. As a small institution, it was feasible to have informal channels of communication from faculty senate and upper administration that simply filtered through to the necessary stakeholder. Those informal channels are no longer sufficient. The lack of communication leads to a lack of cooperation that complicates advising and frustrates both advisors and students. Cooperation needs to be increased between departments taking into account course times, dates, number of seats, and the timeliness of course offerings.

While further research is required, there are implications for best practices that became evident in this case study. Providing a level of continuity in the delivery of accurate information emerged as a key factor of satisfaction in advising. The information gathered indicated a need for increased training in policy, procedure, and delivery of advising function as it extends beyond registration. Preliminary evidence suggests that there may be a benefit to differentiating between professional advising roles and the role of faculty as mentor.

\section{Limitations and Recommendations for Further Study}

One of the limitations of this study was the low response rate, making the results not necessarily as indicative of the whole as desired. This coupled with 
the sustained growth rate of the institution makes these results less generalizable to other institutions. Future surveys of faculty on their perceptions/attitudes towards advising as well as levels of satisfaction would be useful to gain a clearer understanding. There also needs to be a stronger and lengthier marketing period prior to the release of the study to encourage feedback and a higher response rate. A more comprehensive assessment tool, identifying specific advising functions and correlating those functions to satisfaction levels, would also be beneficial to yield a more detailed picture. While professional advisors on campus responded at $100 \%$, that is most likely due to the fact that there are a limited number of professional advisors on staff, largely housed in a centralized location, and the survey speaks directly to their job description.

On a more global scale, there needs to be additional studies done within the field of academic advising (particularly by professional academic advisors whose presence in research is needed) that specifically target faculty and professional advisor perceptions/attitudes and levels of satisfaction. Having a solid understanding of these factors could lead to significant modifications to how advising is integrated within the requirements of professorship. Additionally, this knowledge could lend support to identifying and implementing the most efficacious advising delivery system(s) for students as they matriculate into college.

There is a need in post-secondary education for both faculty and professional advising. This study indicates that both groups found satisfaction in working with students, but it also highlights key components of the current structure of the process. Faculty members clearly see advising as most fulfilling when they are mentoring novices in their field. Organizationally, this mentoring process between faculty and students in the field could be developed further. Communication and verified, accurate information dispersal is also critical to both groups. This could also be formally addressed institutionally.

\section{References}

Aiken-Wisniewski, S. A., Smith, J. S., \& Troxel, W. G. (2010). Expanding research in academic advising: Methodological strategies to engage advisors in research. The Journal of the National Academic Advising Association, 30(1), 4-13.

Allen, J., \& Smith, C. (2008). Importance of, responsibility for, and satisfaction with academic advising: A faculty perspective. Journal of College Student Development, 49(5), 397-411.

Cook, S. (2009). Important events in the development of academic advising in the United States. The Journal of the National Academic Advising Association, 29(2), $18-40$.

Cuseo, J. (2003). Academic advising and student retention: empirical connections \& systemic interventions. Retrieved from https://apps.uwc.edu/administration/ academicaffairs/esfy/CuseoCollection/Academic\%20Advisement $\% 20$ and $\% 20$ Student\%20Retention.doc 
Cuseo, J. (2003). Assessment of academic advisors and academic advising programs. Retrieved from http://www.nacada.ksu.edu/Commissions/C32/ documents/Cuseo_Marymount1.pdf

Dillon, R. K., \& Fisher, B. J. (2000). Faculty as part of the advising equation: An inquiry into faculty viewpoints on advising. The Journal of the National Academic Advising Association, 20(1), 16-23.

Donnelly, N. (2004). The effect of standards use on academic advisor job satisfaction. The Journal of the National Academic Advising Association, 24(1 \& 2), $34-47$.

Donnelly, N. (2009). A National survey of academic-advisor job satisfaction. The Journal of the National Academic Advising Association, 29(1), 5-23.

Gordon, V. N., Habley, W. R., Grites, T. J., \& Associates (2008). Academic advising: A comprehensive handbook (2nd ed.). San Francisco, CA: Jossey-Bass.

Habley, W. R. (2003). Advisor load. Retrieved from NACADA Clearinghouse of Academic Advising Resources: http://nacada.ksu.edu/Clearinghouse/ AdvisingIssues/advisorload.htm

Habley, W. R. (Ed.) (2004). The status of academic advising: Findings from the ACT sixth national survey. National Academic Advising Association Monograph Series Number 10. Manhattan, KS: NACADA.

Habley, W. R., \& McClanahan, R. (2004). What works in student retention? Four-year public colleges. Retrieved from http://www.act.org/research/policymakers/pdf/droptables/FourYearPublic.pdf

Harrison, E. (2009). Faculty perceptions of academic advising "I don't get no respect." Nursing Education Research, 30(4), 229-233.

Herzberg, F. (1968). One more time: How do you motivate employees? Harvard Business Review, 46(1), 53-62.

Lotkowski, V. A., Robbins, S. B., \& Noeth, R. J. (2004). The role of academic and non-academic factors in improving college retention. ACT policy report. Retrieved from http://inpathways.net/college_retention.pdf

Lynch, M. (2002). Advising at the millennium: Advisor satisfaction and perceived avenues to enhancement. The Journal of the National Academic Advising Association, 22(2), 5-25.

Lynch, M. (2004). A survey of undergraduate student reactions to academic advising. The Journal of the National Academic Advising Association, 24(1 \& 2), 62-74.

Milen, J. F., Berger, J. B., \& Dey, E. L. (2000). Faculty time allocation a study of change over twenty years. The Journal of Higher Education, 71(4), 454-475.

Myers, B. E., \& Dyer, J. E. (2005). Attitudes, value, and preparation of university faculty and administrators for advising. Journal of Agricultural Education, 46(3), 35-46.

NACADA. (2003). Paper presented to the Task force on defining academic advising. Retrieved from the NACADA Clearinghouse of Academic Advising Resources: http://www.nacada.ksu.edu/Clearinghouse/Research_Related/definitions.htm 
Pardee, C. F. (2004). Organizational structures for advising. Retrieved from the NACADA Clearinghouse of Academic Advising Resources:

http://www.nacada.ksu.edu/clearinghouse/advisingissues/org_models.htm

Smith, C. L., \& Allen, J. M. (2006). Essential functions of academic advising: What students want and get. The Journal of the National Academic Advising Association. 26(1), 56-66.

Smith, J. (2008). Expectations for research intensify alongside accountability. Indiana Insight. Spring, 20-23.

Swanson, D. J. (2006). Academic advising of undergraduates in communication: Structural models and service challenges identified by faculty. Ohio Communication Journal. 44, 95-108.

Tinto, V. (1997). Classrooms as communities: Exploring the educational character of student persistence. Journal of Higher Education, 68(6), 599-623. 